\title{
Wide disparities in attitudes and practices regarding Type II sphincter of Oddi dysfunction: a survey of expert U.S. endoscopists
}

Authors

Institutions
Rabindra R. Watson ${ }^{1}$, Jason Klapman ${ }^{2}$, Srinadh Komanduri ${ }^{3}$, Janak N. Shah ${ }^{4}$, Sachin Wani ${ }^{5}$, Raman Muthusamy ${ }^{1}$

${ }^{1}$ UCLA Medical Center - Digestive Diseases, Los Angeles, California, USA

2 Moffitt Cancer Center - Gastrointestinal Oncology, Tampa, Florida, USA

${ }^{3}$ Northwestern University - Gastroenterology, Chicago, Illinois, USA

${ }^{4}$ California Pacific Medical Center - Interventional Endoscopy, IES Lab, San Francisco, California, USA

${ }^{5}$ University of Colorado and Veterans Affairs Medical Center - Gastroenterology, Aurora, Colorado, USA submitted 8 . February 2016 accepted after revision 13. June 2016

\section{Bibliography}

Dol http://dx.doi.org/ 10.1055/s-0042-110789 Published online: 10.8.2016 Endoscopy International Open 2016; 04: E941-E946

(c) Georg Thieme Verlag KG Stuttgart · New York E-ISSN 2196-9736

\section{Corresponding author} Rabindra R. Watson, MD UCLA Medical Center Digestive Diseases 200 Medical Plaza 330-33 Los Angeles California 90095 USA

rabindrawatson@gmail.com
Background: Sphincter of Oddi manometry (SOM) is recommended in the evaluation of suspected Type II sphincter of Oddi dysfunction (SOD2), though its utility is uncertain. Little is known about the practice of expert endoscopists in the United States regarding SOD2.

Methods: An anonymous electronic survey was distributed to 128 expert biliary endoscopists identified from U.S. advanced endoscopy training programs.

Results: The response rate was $46.1 \%$ (59/128). Only $55.6 \%$ received training in SOM, and $49.2 \%$ currently perform SOM. For biliary SOD2, 33.3\% routinely obtain SOM, 33.3\% perform empiric sphincterotomy, and $26.3 \%$ perform single session endoscopic ultrasound/endoscopic retrograde cholangiopancreatography (EUS/ERCP). In contrast, an equal number (35.1\%) favor SOM or single session EUS/ERCP for suspected acute idiopathic recurrent pancreatitis, while $19.3 \%$ would

\section{Introduction}

\section{$\nabla$}

The term sphincter of Oddi dysfunction (SOD) is used to describe a syndrome of biliary type pain or acute idiopathic recurrent pancreatitis related to the function of the sphincter of Oddi [1]. The clinical diagnosis of SOD is based on a combination of clinical characteristics, serum enzyme levels, and imaging findings as outlined in the ROME III and Milwaukee classifications [1]. Most patients who demonstrate abnormalities in all three categories (Type I) will respond to endoscopic therapy with sphincterotomy thus obviating the role of sphincter of Oddi manometry (SOM) in this population [2]. In contrast, a recent randomized controlled trial found no benefit associated with SOM or sphincterotomy in patients with isolated pancreaticobiliary type pain (Type III), eliminating the need for endoscopic retrograde cholangiopancreatography (ERCP) in this population [3]. The optimal evaluation and therapy for perform empiric sphincterotomy. Those who perform SOM believe it to be important in predicting response to treatment compared with those who do not $(71.8 \%$ vs $23.1 \%, P=0.01)$. Yet only $51.7 \%$ of this group performs SOM for suspected SOD2. Most (78.6\%) believe that $<50 \%$ of patients report improvement in symptoms after sphincterotomy. Common reasons for not obtaining SOM included unreliable results (50\%), and procedure-related risks (39.3\%). Most (59.3\%) believe SOD2 is at least in part a functional disorder; only $3.7 \%$ felt SOD is a legitimate disorder of the sphincter of Oddi.

Conclusions: Our survey of U.S.expert endoscopists suggests that SOM is not routinely performed for SOD2 and concerns regarding its associated risks and validity persist. Most endoscopists believe SOD2 is at least in part a functional disorder that will not respond to sphincterotomy in the majority of cases.

those patients with typical pain and only one other criterion for SOD (Type II), however, are less clear [1,4].

SOM is currently recommended in the evaluation of suspected SOD Type II before endoscopic therapy based on the evidence that $60-94 \%$ of patients with a basal pressure $>40 \mathrm{mmHg}$ will respond to therapy $[1,5,6]$. Despite this recommendation, the use of SOM has been limited due to variable definitions of what constitutes an elevated sphincter pressure, perceived procedurespecific risks, and confounding factors attributable to the patient, endoscopist, equipment or choice of sedation [7-9]. As a result, alternative strategies including the use of empiric sphincterotomy and single session endoscopic ultrasound (EUS) with therapeutic ERCP based on structural causes of the patient's symptoms identified by EUS imaging have gained widespread acceptance [10-12]. However, there is a dearth of high quality data comparing these strategies [4-6]. 
In light of the limited available evidence in this patient population and the variety of management options, we sought to evaluate the current attitudes and practices with regard to the utility of SOM for suspected SOD2. To this end, we performed a survey study of expert biliary endoscopists in the United States.

\section{Materials and methods}

$\nabla$

\section{Survey instrument}

A 23-question survey was developed to assess the current practice of expert endoscopists with respect to SOD Type II. Content validity was determined based on a review of relevant literature. Face validity was assessed by detailed interviews with expert biliary endoscopists at five tertiary care centers. The survey was divided into three sections. The first nine questions assessed demographics, training experience, and practice environment. The second section included questions pertaining to preferred treatment strategies of suspected biliary SOD2 and acute idiopathic recurrent pancreatitis, attitudes with regard to both the utility and risk associated with SOM, and attitudes with regard to the diagnosis of SOD itself. The final section contained two additional questions to assess the current state of SOM training in the United States (see Appendix).

\section{Participants and survey distribution}

An invitation to participate in the online survey study was delivered by electronic message to 128 pancreaticobiliary endoscopists identified from advanced endoscopy training programs in the United States listed in the ASGE directory. A second email invitation was then delivered 2 weeks later to maximize response rates. Consent to participate was derived from voluntary completion of the survey. A direct Web link to the survey instrument was provided. No personal identifying information was collected and no incentive for survey completion was provided. Responses were collected using an online survey tool (SurveyMonkey, Palo Alto, California, United States).

\section{Data management and statistical analysis}

Categorical variables were expressed using percentages. The standard $\mathrm{X}^{2}$ test and Fisher's exact test were used for comparisons between groups. Results were calculated per question completed independent of survey completion. All $P$ tests were two-sided, and a $P$ value of $<0.05$ was considered statistically significant. Approval from the institutional review board of UCLA Medical Center was obtained. Statistical analysis was performed using statistical software JMP Pro 11 (SAS, Cary, North Carolina, United States).

\section{Results \\ $\nabla$}

\section{Study population characteristics}

In total, 59 of 128 (46.1\%) subjects completed the survey. Most respondents practice in a tertiary care facility (94.9\%) and completed a third tier advanced endoscopy fellowship (71.2\%), though only $56.9 \%$ of respondents received training in SOM ( Table 1). While the majority currently perform ERCP (94.9\%) and EUS (79.7\%) in their practice, only $49.2 \%$ perform SOM. The vast majority of respondents reported a typical caseload of three or fewer cases of suspected SOD encountered per month. For those who do not perform SOM (50.8\%), SOM is readily available

\begin{tabular}{|c|c|}
\hline Number of respondents & 59 \\
\hline Years in practice (mean $\pm S D$ ) & $14.1 \pm 9.85$ \\
\hline Completed third tier fellowship, no. (\%) & $42(71.2)$ \\
\hline Currently perform ERCP, no. (\%) & $56(94.9)$ \\
\hline Currently perform EUS, no. (\%) & $47(79.7)$ \\
\hline Currently perform SOM, no. (\%) & $29(49.2)$ \\
\hline \multicolumn{2}{|l|}{ Availability of SOM, no. (\%) } \\
\hline Yes, within practice group & $14(48.3)$ \\
\hline Yes, outside practice group & $10(34.8)$ \\
\hline No & $5(17.2)$ \\
\hline Received training in SOM, no. (\%) & $33(56.9)$ \\
\hline Offer training in SOM, no. (\%) & $29(55.6)$ \\
\hline $\begin{array}{l}\text { Believe trainees 'rarely' or 'never' reques } \\
\text { SOM, no. }(\%)\end{array}$ & $32(64)$ \\
\hline
\end{tabular}

ERCP, endoscopic retrograde cholangiopancreatography; EUS, endoscopic ultrasound; SOM, sphincter of Oddi manometry.

Table 2 Preferred management strategy for suspected SOD Type II/acute idiopathic recurrent pancreatitis.

\begin{tabular}{|c|c|}
\hline \multicolumn{2}{|l|}{ Biliary } \\
\hline SOM, no. (\%) & $19(33.3)$ \\
\hline Empiric sphincterotomy, no. (\%) & $19(33.3)$ \\
\hline EUS/ERCP, no. (\%) & $15(26.3)$ \\
\hline \multicolumn{2}{|c|}{ Acute idiopathic recurrent pancreatitis } \\
\hline SOM, no. (\%) & $20(35.1)$ \\
\hline Empiric sphincterotomy, no.(\%) & $11(19.3)$ \\
\hline EUS/ERCP, no. (\%) & $20(35.1)$ \\
\hline
\end{tabular}

ERCP, endoscopic retrograde cholangiopancreatography; EUS, endoscopic ultrasound; SOM, sphincter of Oddi manometry.

either within their practice group (48.3\%) or via outside referral (34.5\%).

\section{Practice patterns}

Despite the availability of SOM, an equivalent number of respondents $(33.3 \%)$ would perform empiric sphincterotomy versus SOM for the management of suspected biliary SOD2 ( Table 2). Moreover, an additional $26.3 \%$ would perform single session EUS \pm sphincterotomy based on EUS findings (duct dilation, stones present) as their initial approach.

In contrast, an equal number of respondents (35.1\%) would perform SOM or single session EUS/ERCP in the management of suspected acute idiopathic recurrent pancreatitis. Only $19.3 \%$ would perform empiric sphincterotomy in this situation. Notably, when restricting analysis to those respondents who routinely perform SOM, only $51.7 \%$ would do so as part of their endoscopic evaluation for suspected biliary or pancreatic SOD2.

\section{Attitudes and training}

Most respondents ( $85.5 \%$ ) believe that patients undergoing SOM for suspected SOD2 will ultimately undergo sphincterotomy. However, the vast majority feel that $<50 \%$ of patients would report improvement in symptoms. In addition, half of respondents cite a lack of reliable results as the reason they do not obtain SOM, while an additional 39.3\% cite procedure-related risks ( $\bullet$ Fig. 1). Overall, endoscopists believe duct dilation (40.7\%), enzyme elevation (61\%), and typical symptoms (50.1\%) are "very important" or "extremely important" in predicting response to treatment. Interestingly, a wide disparity in the perceived importance of SOM pressures was observed, with $37.7 \%$ of respondents believ- 


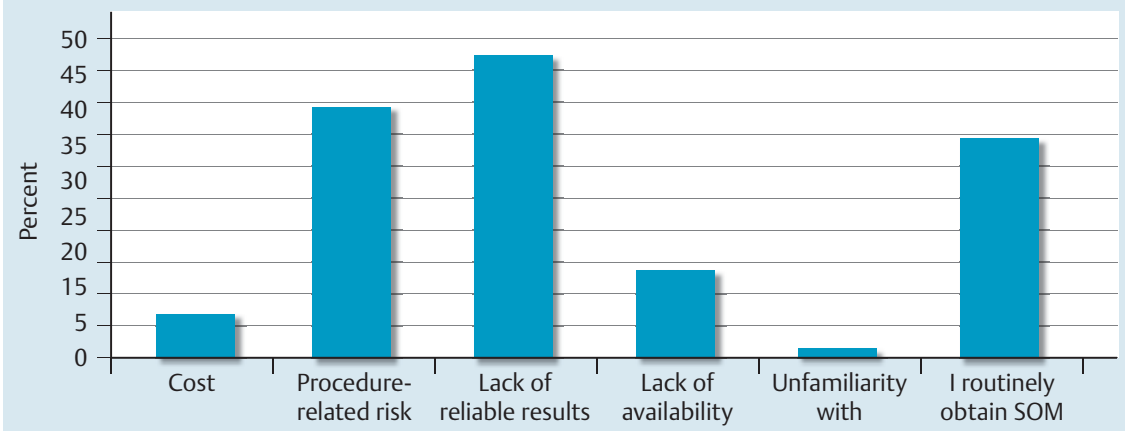

Fig. 1 What are your reasons for not obtaining SOM?*

${ }^{*}$ Respondents may select more than one response. SOM: sphincter of Oddi manometry.

ing them to be "not important" or "not very important", while an equal percentage found them "very important" or "extremely important". A significantly greater percentage of those who perform SOM believe them "very important" or "extremely important" compared with those who do not ( 71.8 vs $23.1 \%, P=0.01)$. No significant difference was seen in the perceived value of duct dilation, enzyme elevation or symptoms between these groups (৫ Table 3).

Regarding the diagnosis of SOD2, half of respondents believe SOD to be at least in part a functional gastrointestinal disorder, and only $3.7 \%$ of those surveyed believe SOD to be a legitimate pathologic disorder of the sphincter of Oddi ( $\mathbf{F i g . 2}$ ). Of the 52 respondents who reported offering training in advanced endoscopy, only $55.8 \%$ currently provide training in SOM. In addition, these respondents report that $64 \%$ of trainees "rarely" or "never" request training in SOM.

\section{Procedural risks and adverse events}

When discussing the procedure-specific risks of SOM with patients, most endoscopists quote a rate of complications of $>15 \%$. Accordingly, $31 \%$ of respondents who perform SOM routinely admit patients following this procedure, and the majority (84.7\%) of all respondents will place pancreatic duct stents following endoscopic intervention.

\section{Discussion}

This survey study of expert pancreaticobiliary endoscopists demonstrates substantial heterogeneity in the diagnostic approach to suspected SOD2 in the United States. Despite the longstanding recommendation for the use of SOM as suggested in the Milwaukee and Rome III guidelines, the majority of respondents do not adhere to this protocol. Endoscopists are instead relying on either empiric sphincterotomy or EUS-directed ERCP in lieu of SOM. The reasons behind the varied approaches are multifactorial, though our data provide some novel insight into the opinions and practices of this cohort.

It is evident that endoscopists remain skeptical regarding the utility of SOM and its impact on management decisions. This skepticism is reflected in the beliefs held by half of respondents that the data supplied by manometry is unreliable, and that most believe that patients will ultimately undergo sphincterotomy regardless of SOM results. Furthermore, as half of the respondents believe SOD to be at least in part a functional disorder, these endoscopists may opt to avoid this diagnostic test. Indeed such uncertainty regarding the role of SOM in suspected SOD has been well documented in the existing literature, with SOM failing to consis-
Table 3 Variables believed to be 'important' or 'extremely important' in predicting response to treatment.

\begin{tabular}{|llll|}
\hline Variable & $\begin{array}{l}\text { Perform SOM, } \\
\text { no. }(\%)\end{array}$ & $\begin{array}{l}\text { Do not perform } \\
\text { SOM, no. }(\%)\end{array}$ & P value \\
\hline Duct dilation & $11(41)$ & $13(48.1)$ & $0.483^{*}$ \\
\hline Enzyme elevation & $18(66.7)$ & $18(66.7)$ & $1^{*}$ \\
\hline Symptoms & $17(62)$ & $14(51.9)$ & $0.65^{*}$ \\
\hline SOM pressure & $14(71.8)$ & $6(23.1)$ & $0.01^{*}$ \\
\hline
\end{tabular}

SOM, sphincter of Oddi manometry.

* Fisher's Exact Test.

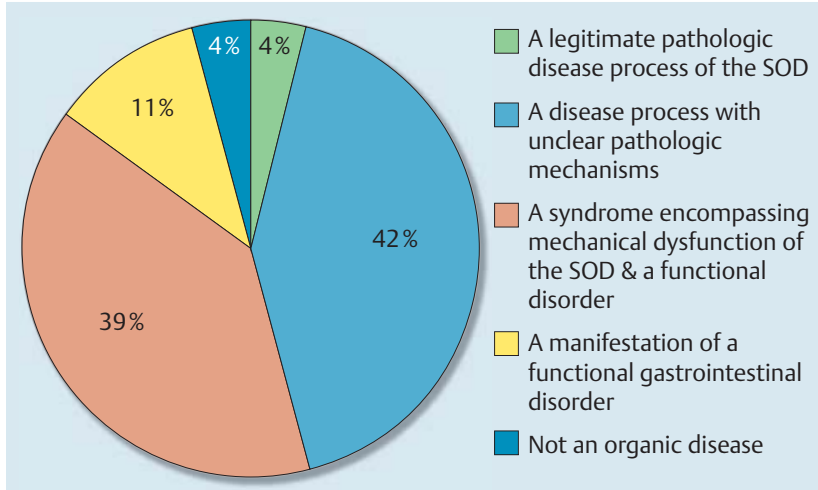

Fig. 2 Which best describes your opinion regarding SOD2? SOD: sphincter of Oddi dysfunction.

tently predict response to sphincterotomy across three randomized trials and several cohort studies [4-6,13].

Our results also demonstrate that those who perform SOM place significantly greater importance on SOM data in predicting symptom response to sphincterotomy than those who do not. However, it is notable that only approximately half of those who perform SOM would actually use the procedure in the evaluation of SOD2. Whether these physicians perform single session EUS/ ERCP or empiric sphincterotomy in this situation was not assessed, though the apparent disparity between belief and clinical practice emphasizes the uncertain role of SOM in this situation.

While it is evident that an elevated risk of pancreatitis is associated with performance of ERCP in patients with SOD, it is increasingly recognized that this risk exists irrespective of the procedures performed, including SOM [13-16]. Despite this evidence to the contrary, nearly $40 \%$ of endoscopists surveyed continue to avoid SOM due to perceived procedure-specific risk. This suggests a persistent bias against SOM-related risks, even amongst expert U.S.endoscopists at tertiary care facilities, and may explain the frequent use of EUS as an alternative diagnostic test. 
Unsurprisingly, these perceived limitations of SOM are reflected in current advanced endoscopy training as only approximately half of surveyed expert endoscopists have received training in SOM and currently offer training in this procedure. Furthermore, as most find that trainees do not actively seek training in this technique, it is plausible that dissemination of this procedure will decline in the United States in the near future, further limiting its applicability in clinical practice.

This study has limitations inherent to survey-based investigations, including recall and selection bias. While an anonymous survey will mitigate reporting bias associated with voluntary reporting of outcomes, this remains a possible limitation. As this investigation was directed towards U.S.expert pancreaticobiliary endoscopists at tertiary care facilities, our results may not be generalizable to the endoscopic community at large. However, as the use of SOM is generally limited to referral centers, we sought to specifically capture the practices of this physician group.

In conclusion, despite previous recommendations for the use of SOM in the evaluation of SOD2, our study suggests that SOM is not routinely performed in clinical practice, as many experts question its validity and continue to harbor reservations with regard to the associated risks of the test itself. Given the current disparity in practice patterns, reliance on EUS-directed ERCP, and lack of high quality evidence to guide management of suspected SOD2, further prospective studies delineating the optimal evaluation and management of this controversial diagnosis are needed.

\section{Competing interests: None}

\section{References}

1 Behar J, Corazziari E, Guelrud $M$ et al. Functional gallbladder and sphincter of oddi disorders. Gastroenterology 2006; 130: 1498-1509

2 Thatcher BS, Sivak MV, Tedesco FJ et al. Endoscopic sphincterotomy for suspected dysfunction of the sphincter of Oddi. Gastrointest Endosc 1987; 33: $91-95$

3 Cotton PB, Durkalski V, Romagnuolo J et al. Effect of endoscopic sphincterotomy for suspected sphincter of Oddi dysfunction on pain-related disability following cholecystectomy: the EPISOD randomized clinical trial. JAMA 2014; 311: $2101-2109$

4 Toouli J, Roberts-Thomson IC, Kellow J et al. Manometry based randomised trial of endoscopic sphincterotomy for sphincter of Oddi dysfunction. Gut 2000; 46: 98-102

5 Geenen JE, Hogan WJ, Dodds WJ et al. The efficacy of endoscopic sphincterotomy after cholecystectomy in patients with sphincter-of-Oddi dysfunction. NEJM 1989; 320: $82-87$

6 Sherman S, Lehman G, Jamindar P et al. Efficacy of endoscopic sphincterotomy and surgical sphincteroplasty for patients with sphincter of Oddi dysfunction (SOD): randomized, controlled study. Gastrointest Endosc 1994; 40: P125

7 Guelrud M, Mendoza S, Rossiter G et al. Sphincter of Oddi manometry in healthy volunteers. Dig Dis Sci 1990; 35: 38 - 46

8 Maldonado ME, Brady PG, Mamel JJ et al. Incidence of pancreatitis in patients undergoing sphincter of Oddi manometry (SOM). Am J Gastroenterol 1999; 94: 387-390

9 Smithline A, Hawes R, Lehman G. Sphincter of Oddi manometry: interobserver variability. Gastrointest Endosc 1993; 39: 486 - 491

10 Coyle WJ, Pineau BC, Tarnasky PR et al. Evaluation of unexplained acute and acute recurrent pancreatitis using endoscopic retrograde cholangiopancreatography, sphincter of Oddi manometry and endoscopic ultrasound. Endoscopy 2002; 34: 617-623

11 Arguedas MR, Linder JD, Wilcox CM. Suspected sphincter of Oddi dysfunction type II: empirical biliary sphincterotomy or manometryguided therapy? Endoscopy 2004; 36: 174-178

12 Khashab MA, Watkins JL, McHenry L et al. Frequency of sphincter of Oddi dysfunction in patients with previously normal sphincter of Oddi manometry studies. Endoscopy 2010; 42: 369-374

13 Petersen BT. An evidence-based review of sphincter of Oddi dysfunction: part I, presentations with "objective" biliary findings (types I and II). Gastrointest Endosc 2004; 59: 525-534

14 Sheehan SJ, Lee JH, Wells CK et al. Serum amylase, pancreatic stents, and pancreatitis after sphincter of Oddi manometry. Gastrointest Endosc 2005; 62: 260-265

15 Tarnasky PR, Palesch YY, Cunningham JT et al. Pancreatic stenting prevents pancreatitis after biliary sphincterotomy in patients with sphincter of Oddi dysfunction. Gastroenterology 1998; 115: 1518 1524

16 Singh P, Gurudu SR, Davidoff S et al. Sphincter of Oddi manometry does not predispose to post-ERCP acute pancreatitis. Gastrointest Endosc 2004; 59: 499-505 


\section{Appendix}

1.What is the setting of your practice?

$\square$ Tertiary referral center

$\square$ Multispeciality Group

$\square$ HMO

$\square$ Solo Practice

2. Where did you receive your gastroenterology fellowship training?

Program Name:

City, State:

3.If applicable, where did you receive your third tier ( $4^{\text {th }}$ year) advanced endoscopy fellowship

Program Name:

City, State:

4. Please check all that apply to your training:

If yes, number of procedures

$\square$ Training in EUS during 3-year fellowship

$\square$ Training in EUS during dedicated $4^{\text {th }}$ year

$\square$ Training in ERCP during 3-year fellowship

$\square$ Training in ERCP during dedicated $4^{\text {th }}$ year

$\square$ Training in sphincter of Oddi manometry

5. How many years have you been in practice

6. Please check all that apply to your current practice:

$\square$ I perform EUS

$\square$ I perform ERCP

$\square$ I perform sphincter of Oddi manometry (SOM)

$\square$ None of the above

7.If you perform ERCP, on average, how many ERCP's do you perform per year?

$\square$ I do not perform ERCP

$\square 0-100$

$\square 101-250$

$\square 251-500$

$\square 501-1000$

$>1000$

8. On average, how many patients with suspected sphincter of Oddi dysfunction (SOD) do you evaluate per month?

$\square 0-3$

$\square 4-7$

$\square 8-12$

$\square 12+$

9. If you do not perform ERCP, is sphincter of Oddi manometry (SOM) readily accessible for the diagnostic work up of patients with suspected SOD?

$\square$ Yes, within my practice group

$\square$ Yes, outside referral

$\square$ No

10. What is your typical practice in evaluating cases of suspected TYPE II BILIARY SOD?

$\square$ Refer Patient

$\square$ ERCP with Sphincter of Oddi Manometry \pm subsequent endotherapy as indicated
Empiric sphincterotomy

EUS \pm ERCP with biliary sphincterotomy based on EUS findings (duct dilation, stones, etc.)

11. What is your typical practice in evaluating cases of suspected TYPE II PANCREATIC SOD?

$\square$ Refer Patient

$\square$ ERCP with Sphincter of Oddi Manometry \pm subsequent endotherapy as indicated

$\square$ Empiric sphincterotomy

$\square$ EUS \pm ERCP with biliary sphincterotomy based on EUS findings (duct dilation, stones, etc.)

12. What is your quoted rate of complications when discussing SOM with patients?
$\square 0-5 \%$
$\square 6-10 \%$
$\square 11-15 \%$
$\square 16-20 \%$
$\square>20 \%$

13.In your practice do you (Check all that apply):

$\square$ Routinely admit patients after SOM

$\square$ Routinely admit patients after ERCP with sphincterotomy

$\square$ I do not routinely admit patients after SOM or ERCP with sphincterotomy

14. Do you routinely place pancreatic duct stents following ERCP in patients with suspected SOD? (Check all that apply):

$\square$ Yes, after biliary SOM

$\square$ Yes, after pancreatic SOM

$\square$ Yes, after ERCP with biliary sphincterotomy

$\square$ Yes, after ERCP with pancreatic sphincterotomy

$\square$ No, I do not routinely place pancreatic duct stents after SOM or sphincterotomy

15. In your opinion, what percentage of patients with suspected biliary or pancreatic type II SOD ultimately undergo sphincterotomy following SOM?
$\square 0-25 \%$
$\square 26-50 \%$
$\square 51-75 \%$
$76-100 \%$

16. In your opinion, what percentage of patients report a subjective improvement of symptoms after biliary sphincterotomy for treatment of biliary SOD type 2 ?
$\square 0-25 \%$
$\square 26-50 \%$
$\square 51-75 \%$
$76-100 \%$

17. In your opinion, what percentage of patients report a subjective improvement of symptoms after pancreatic sphincterotomy for treatment of pancreatic SOD type 2 ?
$\square 0-25 \%$
$\square 26-50 \%$
$\square 51-75 \%$
$\square 76-100 \%$ 
18. If you do not routinely obtain SOM in the evaluation of suspected SOD2, what are your reasons? (check all that apply):

$\square$ Cost

$\square$ Procedure-related risks (Post-ERCP Pancreatitis)

$\square$ Lack of reliable results (false positive and false negative results)

$\square$ Lack of availability

$\square$ Unfamiliarity with the procedure

19. How important are each of the following in predicting response to treatment of SOD type 2 ?

\section{Duct dilation}

Extremely Important

Very Important

Somewhat Important

Not Very Important

Not Important

\section{Enzyme elevation}

Extremely Important

Very Important

Somewhat Important

Not Very Important

Not Important

History (symptoms)

Extremely Important

Very Important

Somewhat Important

Not Very Important

Not Important

\section{SOM pressures}

Extremely Important

Very Important

Somewhat Important

Not Very Important

Not Important
For the following case presentation, please choose your next step in management:

20. A 45-year-old otherwise healthy woman presents with intermittent right upper quadrant pain exacerbated by fatty meals, normal serum liver and pancreatic enzyme levels, and a dilated common bile duct of $14 \mathrm{~mm}$ and normal gallbladder on trans-abdominal ultrasound.

$\square$ Perform ERCP with biliary sphincterotomy

$\square$ Perform single session EUS \pm ERCP with biliary sphincterotomy if EUS corroborates duct dilation

$\square$ Perform ERCP with SOM and possible sphincterotomy as dictated by manometry

$\square$ Obtain MRCP and if abnormal, perform ERCP with sphincterotomy

$\square$ Trial of anti-spasmodics

21. Which best describes your opinion regarding sphincter of Oddi dysfunction?

$\square$ A manifestation of a functional gastrointestinal disorder

$\square$ A controversial disease process with unclear pathologic mechanisms

$\square$ A syndrome encompassing mechanical dysfunction of the sphincter of Oddi as well as a functional GI disorder

$\square$ A legitimate disease process with unclear pathologic mechanisms

$\square$ Not an organic disease

22. Do you offer training in SOM to advanced endoscopy fellows?

$\square$ Yes

$\square$ No

23. How often to advanced endoscopy fellows request training in SOM?

Never Rarely Sometimes Often Always 